\title{
Harga Opsi Call Tipe Eropa menggunakan Simulasi Monte Carlo Standar dan Teknik Antithetic Variates
}

\author{
Anisah Mardiah Qur'ani \\ Universitas Islam Negeri Alauddin Makassar \\ Irwan Kasse \\ Universitas Islam Negeri Alauddin Makassar,irwan.msi@uin-alauddin.ac.id \\ Ilham Syata \\ Universitas Islam Negeri Alauddin Makassar
}

\begin{abstract}
ABSTRAK. The European call option is a contract that gives the contract holder the right to buy a certain asset at a price and a certain period of time, which is the execution time at maturity. This study aims to determine the accuracy of the simulation results of stock prices to determine the price of European call options from simulation of standard Monte Carlo and the antithetic variates technique using RStudio software. The results of the simulation of the two methods will approach the option price of the analytic solution. Analytical solutions in this study use the BlackScholes model to obtain a standard price that serves to compare the two methods. The call option price of the European type uses the Black-Scholes model as a benchmark is $\$ 14.20281$. In the $1.000 .000^{\text {th }}$ standard Monte Carlo simulation, the call option price converges to $\$ 14.69786$ with a standard error of 0.019 , while the $100.000^{\text {th }}$ Monte Carlo-antithetic variates produces a call option price converges at $\$ 14.69801$ with a standard error of 0.043 . The results of this study indicate that Monte Carlo simulation with antithetic variates technique is more accurate because it produces an option value faster to converge with a relatively smaller standard error.
\end{abstract}

Kata Kunci: European Option, Monte Carlo, Monte Carlo-Antithetic Variates, Black-Scholes

\section{PENDAHULUAN}

Investasi merupakan salah satu bentuk penanaman modal dengan harapan untuk mendapatkan keuntungan di masa yang akan datang. Investasi dapat dilakukan dalam jangka pendek maupun jangka panjang. Investasi jangka pendek dapat dilakukan dengan menabung di Bank, deposito, dan lain sebagainya. Sedangkan investasi jangka panjang dapat dilakukan dengan investasi emas, tanah/bangunan, maupun melalui pasar modal.Pasar modal merupakan tempat jual beli berbagai macam instrument keuangan, yaitu saham, obligasi, reksadana, dan lain sebagainya.

Dalam dunia keuangan, terdapat suatu objek keuangan yang dianggap menguntungkan para investor yang disebut financial derivative dimana harganya bergantung pada pergerakan harga suatu underlying asset. Salah satu instrumen finansial yang dapat dikategorikan dalam kelompok derivative adalah opsi. Opsi merupakan suatu kontrak yang memberikan hak kepada pemegang/investor untuk membeli/menjual aset pada periode waktu tertentu dan dengan harga tertentu. Opsi dapat dibedakan menjadi dua berdasarkan periode waktu pelaksanaannya (expiration date), yaitu opsi tipe Eropa dan opsi tipe Amerika. Selain itu, berdasarkan jenis hak yang diberikan, opsi dibedakan menjadi opsi beli (call option) dan opsi jual (put option).

Banyak metode yang bisa digunakan untuk menentukan harga opsi tipe Eropa. Simulasi Monte Carlo merupakan salah satu metode pendekatan numerik yang dapat digunakan dalam memperkirakan suatu harga opsi, baik yang memiliki formula analitik maupun tidak memiliki formula analitik. Dalam menganalisis simulasi Monte Carlo, peningkatan jumlah sampel akan mengurangi variansi. Untuk meningkatkan keakuratan dan efisiensi dari simulasi Monte Carlo, diperlukan teknik reduksi variansi. Salah satu teknik reduksi variansi yaitu teknik antithetic variates yang melibatkan perhitungan dua nilai derivatif sehingga akan mengurangi nilai standar deviasi.

Berdasarkan uraian di atas, maka penulis tertarik untuk meneliti tentang "Harga Opsi Tipe Eropa Menggunakan Simulasi Monte Carlo Standar dan Teknik Antithetic Variates.

\section{2. .TINJAUAN PUSTAKA}

\section{Investasi}

Investasi adalah sejumlah dana atau sumber daya lainnya yang dilakukan pada saat ini, dengan 
tujuan memperoleh sejumlah keuntungan di masa akan datang.[1]

\section{Opsi}

Opsi (option) merupakan kontrak yang memberikan hak kepada pemilik atau pemegangnya untuk membeli atau menjual sejumlah tertentu saham opsi (optioned stock) suatu perusahaan tertentu dengan harga tertentu dalam waktu atau tanggal jatuh tempo tertentu (expiration date). [2]

Berdasarkan periode waktu penggunaannya, opsi dibedakan menjadi dua, yaitu :

1. Opsi tipe Eropa (European Option), adalah opsi yang dapat digunakan hanya pada saat tanggal jatuh tempo.

2. Opsi tipe Amerika (American Option), adalah opsi yang dapat digunakan sebelum tanggal jatuh tempo atau pada saat tanggal jatuh tempo.

Sedangkan berdasarkan jenis hak yang diberikan kepada pemegangnya, opsi dibedakan menjadi dua, yaitu:

1. Opsi call yang merupakan opsi yang memberikan hak kepada pemegangnya untuk membeli saham pada harga tertentu sampai batas waktu yang telah ditentukan.Secara sistematis, harga opsi call dinyatakan dengan persamaan yaitu

$$
C=\max \left(S_{T}-K, 0\right)
$$

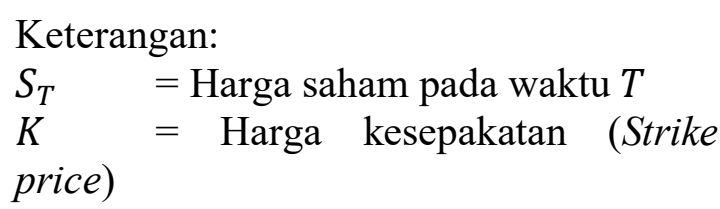

2. Opsi put yang merupakan opsi yang memberikan hak kepada pemegangnya untuk menjual saham pada harga tertentu sampai dengan batas waktu yang ditentukan. Secara sistematis, harga opsi put dinyatakan dengan persamaan yaitu:

$$
P=\max \left(K-S_{T}, 0\right)
$$

Keterangan:

$S_{T} \quad=$ Harga saham pada waktu $T$
$K=$ Harga kesepakatan (Strike price)

\section{Model Black-Scholes}

Adapun persamaan Black-Scholes untuk menghitung harga opsi call tipe Eropa adalah sebagai berikut:[3]

$$
C=S_{0} N\left(d_{1}\right)-K e^{-r T} N\left(d_{2}\right)
$$

dengan,

$$
\begin{gathered}
d_{1}=\frac{\ln \left(\frac{S_{0}}{K}\right)+\left(r+\frac{1}{2} \sigma^{2}\right) T}{\sigma \sqrt{T}} \\
d_{2}=\left(\frac{\ln \left(\frac{S_{0}}{K}\right)+\left(r+\frac{1}{2} \sigma^{2}\right) T}{\sigma \sqrt{T}}\right)-\sigma \sqrt{T}
\end{gathered}
$$

$d_{2}=d_{1}-\sigma \sqrt{T}$

dimana :

$C \quad=$ Harga opsi call Eropa

$S_{0} \quad=$ Harga saham awal

$K=$ Harga kesepakatan (strike price)

$N\left(d_{1}\right)=$ Fungsi distribusi normal kumulatif

$N\left(d_{2}\right)=$ Fungsi distribusi normal kumulatif

$T \quad=$ Waktu jatuh tempo

$r \quad=$ Tingkat bunga bebas risiko

$\sigma \quad=$ Volatilitas harga saham

$\sigma^{2} \quad=$ Variansi

\section{Estimasi Return,Variansi dan Volatilitas Harga Saham}

\section{Return Saham}

Return saham merupakan hasil yang diperoleh dari suatu investasi saham, berupa tingkat keuntungan yang ditandai dengan nilai return saham positif (capital gain) atau kerugian yang ditandai dengan nilai returnsaham negatif (capital lost).

Adapun persamaan untuk mencari nilai return saham adalah :

$R_{(t)}=\frac{S_{(t)}-S_{(t-1)}}{S_{(t-1)}}$

Keterangan :

$R_{(t)} \quad=$ Return saham

$S_{(t)} \quad=$ Harga saham pada periode sekarang

$S_{(t-1)}=$ Harga saham pada periode sebelumnya

\section{Variansi}

Variansi adalah suatu ukuran penyebaran data yang digunakan untuk mengetahui seberapa jauh penyebaran data dari nilai ekspektasinya. Jika nilai variansi kecil, maka penyebaran data return saham mendekati ekspektasi return. Sebaliknya, 
jika nilai variansi besar, maka penyebaran data return sahamnya menjauhi nilai ekspektasi.

Adapun persamaan untuk mencari nilai variansi adalah sebagai berikut:

$$
\text { var }=\frac{\sum_{i=0}^{n}\left(R_{(t)}-E\left(R_{(t)}\right)\right)^{2}}{n-1}
$$

dimana untuk menghitung nilai ekspektasi return (nilai yang diharapkan) dapat dilakukan dengan menggunakan persamaan sebagai berikut :

$$
E\left(R_{(t)}\right)=\frac{\sum_{i=0}^{n} R_{\left(t_{i}\right)}}{n}
$$

Keterangan :

$$
n=\text { Jumlah data saham }
$$

\section{Volatilitas}

Volatilitas adalah tingkat ketidakpastian yang terjadi dalam bursa saham yang akan mempengaruhi harga opsi.

Adapun persamaan untuk mencari nilai volatilitasnya adalah sebagai berikut:

$\sigma=\frac{1}{\sqrt{\tau}} \sqrt{\operatorname{Var}}$

Dimana $\tau=\frac{1}{T}$ dengan $T$ adalah jumlah hari aktif perdagangan dalam satu tahun yaitu 252 hari. Sehingga nilai $\tau=\frac{1}{252}$. [4]

\section{Opsi Eropa Simulasi Monte Carlo}

Metode Monte Carlo dikenal dengan istilah sampling simulation atau Monte Carlo Sampling Technique. Metode ini menggunakan data sampling yang telah ada (historical data) dan telah diketahui distribusi datanya. Metode Monte Carlo memanfaatkan strong law of large number dalam melakukan perhitungan, artinya semakin banyak variabel acak yang digunakan, maka akan semakin baik pula pendekatan nilai eksaknya.[5] Penentuan harga opsi dalam metode Monte Carlo dipengaruhi oleh harga saham dalam keadaan risiko netral $(\mu=r)$. Dalam penggunaan metode Monte Carlo, harga saham yang digunakan mengikuti model geometric Brownian motion dengan persamaan:

$S_{T}=S_{0} \cdot \exp \left(\left(\mu-\frac{\sigma^{2}}{2}\right) T+\sigma Z \sqrt{T}\right)(2$

dengan $S_{T}$ adalah harga saham pada waktu $t, S_{0}$ adalah harga saham awal $(t=0), \mu$ adalah ekspektasi return saham, dan $\sigma$ adalah volatilitas harga saham.
Secara numerik, simulasi Monte Carlo memerlukan perhitungan nilai opsi call yang diharapkan dari opsi call tipe Eropa pada saat jatuh tempo dan dikalikan dengan bilangan eksponen dengan bunga yang diberlakukan. Nilai opsi call tipe Eropa $(C)$ kemudian dihitung dengan menggunakan persamaan berikut :

$$
C=e^{-r T} \max (S(T)-K, 0)
$$

Setelah melakukan simulasi, nilai opsi call yang diharapkan diperoleh dengan menghitung ratarata dari penaksir nilai opsi call yang dihasilkan. Misalkan $C_{i}$ menyatakan penaksir dari nilai opsi call yang diperoleh dalam simulasi dan $M$ adalah banyaknya simulasi, maka nilai opsi call yang diharapkan, yaitu :

$C=\frac{1}{M} \sum_{i=1}^{M} C_{i}$

$C=\frac{1}{M} \sum_{i=1}^{M} e^{-r T} \max (S(T)-K, 0)$

$C=e^{-r T} \frac{1}{M} \sum_{i=1}^{M} \max (S(T)-K, 0)(2.12)$

dan variansi opsi call dihitung dengan :

$$
\sigma_{C}{ }^{2}=\frac{1}{M-1} \sum_{i=1}^{M}\left(C_{i}-C\right)^{2}
$$

Jika $\omega$ adalah standar deviasi dan $M$ adalah banyaknya simulasi, maka galat yang dihasilkan dari harga opsi call, yaitu :

$$
S E=\frac{\omega}{\sqrt{M}}
$$

\section{Teknik Antithetic Variates}

Perhitungan harga opsi menggunakan teknik antithetic variates mengikuti gerak Brown geometric dengan cara membangkitkan dua bilangan acak berdistribusi normal.

$S_{T(1)}=S_{0} \cdot \exp \left(\left(\mu-\frac{\sigma^{2}}{2}\right) T+\sigma Z \sqrt{T}\right)$

$S_{T(2)}=S_{0} \cdot \exp \left(\left(\mu-\frac{\sigma^{2}}{2}\right) T-\sigma Z \sqrt{T}\right)$

(2.16)

Berdasarkan Persamaan (2.15) dan Persamaan (2.16), harga opsi $(\vec{f})$ dapat dihitung dengan menggunakan persamaan berikut :

$\bar{f}=\frac{f_{1}+f_{2}}{2}$

dimana :

$f_{1}=e^{-r T} \frac{1}{M} \sum_{i=1}^{M} \max \left(S_{\left(T_{1}\right)}-K, 0\right)$
$f_{2}=e^{-r T} \frac{1}{M} \sum_{i=1}^{M} \max \left(S_{\left(T_{2}\right)}-K, 0\right)$ 
Persamaan variansi dalam teknik antithetic variates dapat dinyatakan dalam persamaan sebagai berikut.

$$
\begin{aligned}
& \operatorname{var}(\bar{f})=\frac{1}{4}\left[\operatorname{var}\left(f_{1}\right)+\operatorname{var}\left(f_{2}\right)\right. \\
& \left.+2 \operatorname{cov}\left(f_{1}, f_{2}\right)\right] \\
& \operatorname{var}(\bar{f})=\operatorname{var}\left[\frac{1}{2}\left(f_{1}+f_{2}\right)\right]=\frac{1}{4} \operatorname{var}\left[f_{1}\right]+ \\
& \frac{1}{4} \operatorname{var}\left[f_{2}\right]+\frac{1}{2} \operatorname{cov}\left[f_{1}, f_{2}\right]
\end{aligned}
$$

\section{METODOLOGI}

Data yang digunakan berupa data sekunder yaitu data harga penutupan saham harian untuk perusahaan Microsoft Corporation dengan periode 10 Oktober 2017-10 Oktober 2018.

Langkah-langkah yang dilakukan dalam rangka mencapai tujuan penelitian adalah sebagai berikut:

1. Mengambil data historis harga saham harian PT Microsoft Corporation (MSFT)melalui http://www.finance.yahoo.com

2. Menentukan harga saham awal $\left(\mathrm{S}_{0}\right)$.

3. Menghitung volatilitas harga saham berdasarkan data yang ada dengan langkahlangkah sebagai berikut :

a. Menghitung nilai return saham untuk menganalisis apakah saham tersebut mengalami keuntungan atau kerugian.

b. Menghitung variansi dengan menggunakan nilai return yang telah diperoleh.

c. Menghitung volatilitas.

4. Menentukan nilai untuk parameter-parameter yang digunakan dalam menentukan harga opsi saham.

a. Menentukan nilai time to maturity $(T)$.

b. Menentukan harga kesepakatan (strike price) $(K)$.

c. Menentukan tingkat suku bunga bebas risiko $(r)$.

5. Menghitung harga opsi call tipe Eropa menggunakan model Black-Scholes.

6. Menghitung harga opsi call tipe Eropa menggunakan Simulasi Monte Carlo standar.

a. Membangkitkan bilangan acak $Z$ berdistribusi normal.

b. Mensimulasikan harga saham di tiap akhir selang waktu dari awal umur opsi sampai waktu jatuh tempo menggunakan nilai bilangan acak berdistribusi normal.

c. Menghitung nilai derivatif $f$ setelah mendapat harga saham akhir.

d. Mengulangi langkah (a) dan (b) sebanyak $M$ simulasi.

e. Menaksir nilai opsi dengan merataratakan $f$ yang didapatkan dari setiap simulasi.

f. Menghitung harga opsi call tipe Eropa menggunakan simulasi Monte Carlo standar dengan menggunakan Persamaan (2.12).

g. Menentukan keakuratan harga opsi yang diperoleh menggunakan simulasi Monte Carlo standar dengan menghitung nilai error (galat).

7. Menghitung harga opsi call tipe Eropa menggunakan Simulasi Monte Carlo dengan teknik antithetic variates.

a. Membangkitkan dua bilangan acak $Z,-Z$ berdistribusi normal.

b. Mensimulasikan harga saham di tiap akhir selang waktu dari awal umur opsi sampai waktu jatuh tempo menggunakan nilai bilangan acak berdistribusi normal dalam bentuk $(Z,-Z)$.

c. Menghitung nilai derivatif $f_{1}$ dan $f_{2}$ setelah mendapat harga saham akhir.

d. Mengulangi langkah (a) dan (b) sebanyak $M$ simulasi.

e. Menaksir nilai opsi dengan merataratakan $f_{1}$ yang didapatkan dari setiap simulasi.

f. Menaksir nilai opsi dengan merataratakan $f_{2}$ yang didapatkan dari setiap simulasi.

g. Menghitung harga opsi call tipe Eropa menggunakan teknik antithetic variates dengan menggunakan Persamaan (2.17).

h. Menentukan keakuratan harga opsi yang diperoleh menggunakan teknik antithetic variates dengan menghitung nilai error (galat). 


\section{PEMBAHASAN}

Data yang digunakan pada penelitian ini adalah data sekunder berupa data harga penutupan (closing price) harian dari MSFT. Data tersebut merupakan data harga penutupan harian selama satu tahun yang dimulai dari 10 Oktober 2017 sampai dengan 10 Oktober 2018 sebanyak 252 data saham yang diperoleh dari http://www.finance.yahoo.com. Langkahlangkah dalam menentukan harga opsi call Eropa adalah sebagai berikut:

1. Menentukan harga saham awal $\left(S_{0}\right)$ yang akan dijadikan acuan dalam perhitungan ini yaitu sebesar $\$ 106.16$.

2. Menghitung volatilitas harga saham berdasarkan data yang ada dengan langkahlangkah sebagai berikut:

a. Menentukan nilai return saham menggunakan persamaan berikut:

$$
R_{(t)}=\frac{S_{(t)}-S_{(t-1)}}{S_{(t-1)}}
$$

Kemudian nilai ekspektasireturn saham dapat dihitung dengan menggunakan persamaan (2.8):

$$
E\left(R_{(t)}\right)=\frac{\sum_{i=0}^{n} R_{\left(t_{i}\right)}}{n}
$$

dan diperoleh nilai ekspektasi return saham MSFT sebesar 0.001419928.

b. Setelah diperoleh nilai return dan ekspektasi return saham MSFT, dihitung nilai variansi dari saham MSFT menggunakan persamaan berikut:

$$
\text { var }=\frac{\sum_{i=0}^{n}\left(R_{(t)}-E\left(R_{(t)}\right)\right)^{2}}{n-1}
$$

Dengan bantuan software $R$ diperoleh nilai variansi dari saham MSFT sebesar 0.0002171269 .

c. Volatilitas tahunan saham dihitung dengan menggunakan persamaan berikut:

$$
\sigma=\frac{1}{\sqrt{\tau}} \sqrt{\operatorname{Var}}
$$

sehingga diperoleh volatilitas tahunan saham MSFT sebesar 0.23391447.

3. Menentukan parameter-parameter yang digunakan dalam menentukan harga opsi diantaranya:

a. Nilai time to maturity (T) atau waktu jatuh tempo yang digunakan adalah selama satu tahun. b. Strike price $(K)$ adalah suatu harga yang disepakati di awal kontrak opsi antara penerbit dan pemegang opsi. Harga kesepakatan yang digunakan dalam penelitian ini yaitu sebesar $\$ 100$.

c. Tingkat suku bunga bebas risiko $(r)$ yang digunakan dalam penelitian ini merupakan tingkat suku bunga Bank Amerika yaitu sebesar $2,25 \%$ yang diperoleh dari http://www.fxstreet. web.id/economic-calendar/ interest-ratestable/.

4. Menghitung harga opsi call tipe Eropa menggunakan model Black-Scholes.

Secara manual, penghitungan harga opsi call standar dengan menggunakan model Black Scholes dapat dihitung sebagai berikut:

a. Menghitung nilai $d_{1}$ :

$$
\begin{gathered}
d_{1}=\frac{\ln \left(\frac{S_{0}}{K}\right)+\left(r+\frac{1}{2} \sigma^{2}\right) T}{\sigma \sqrt{T}} \\
=\frac{\ln \left(\frac{106.16}{100}\right)+\left(0.0225+\frac{1}{2} 0.0002171269\right) 1}{0.23391447 \sqrt{1}} \\
d_{1}=0.352205
\end{gathered}
$$

b. Menghitung nilai $d_{2}$ :

$$
\begin{gathered}
d_{2}=d_{1}-\sigma \sqrt{T} \\
d_{2}=0.352205-0.23391447 \sqrt{1} \\
d_{2}=0.1182905
\end{gathered}
$$

c. Tentukan nilai $N\left(d_{1}\right)$ :

$$
\begin{gathered}
N\left(d_{1}\right)=N(0.352205) \\
N\left(d_{1}\right)=0.6376577
\end{gathered}
$$

d. Tentukan nilai $N\left(d_{2}\right)$ :

$$
\begin{gathered}
N\left(d_{2}\right)=N(0.1182905) \\
N\left(d_{2}\right)=0.5470813
\end{gathered}
$$

Dengan nilai dari $N\left(d_{1}\right)$ dan $N\left(d_{2}\right)$ merupakan fungsi distribusi normal kumulatif untuk $d_{1}$ dan $d_{2}$. Nilai dari $N\left(d_{1}\right)$ dan $N\left(d_{2}\right)$ dapat dilihat di table kurva normal atau dapat digunakan fungsi pnorm pada software $R$.

e. Menghitung nilai opsi call tipe Eropa dengan persamaan (2.3):

$$
\begin{gathered}
C=S_{0} N\left(d_{1}\right)-K e^{-r T} N\left(d_{2}\right) \\
C=106.16 \cdot 0.6376577 \\
-100 \cdot e^{-0.0225(1)} \\
\cdot 0.5470813 \\
C=67.69374-53.49094 \\
C=14.2028
\end{gathered}
$$


Harga opsi call tipe Eropa yang dihitung dengan menggunakan model Black-Scholes akan dijadikan tolak ukur harga standar opsi call yang akan dinegosiasikan antara penjual dan pembeli opsi call. Harga standar ini nantinya akan dibandingkan dengan harga opsi call yang dihitung dengan menggunakan simulasi Monte Carlo standar dan simulasi Monte Carlo dengan teknik antithetic variates, untuk mengetahui metode mana yang hasilnya mendekati harga standar.

5. Menghitung harga opsi call tipe Eropa menggunakan simulasi Monte Carlo dan teknik Antithetic Variates.

Simulasi Monte Carlo adalah simulasi yang menggunakan bilangan acak berdistribusi normal untuk mensimulasikan harga saham guna mendapatkan harga opsi call. Persamaan yang digunakan untuk mensimulasikan harga saham adalah persamaan (2.10). Teknik Antithetic Variates adalah salah satu teknik reduksi variansi yang dapat memperkecil galat yang dihasilkan guna meningkatkan efisiensi metode Monte Carlo dari sisi variansi. Pada teknik Antithetic
Variates, persamaan yang digunakan untuk mensimulasikan harga saham sama dengan persamaan pada simulasi Monte Carlo, yang membedakan hanya pada bilangan acak $Z$ saja. Pada teknik Antithetic Variates melibatkan dua peubah acak berdistribusi normal $(Z,-Z)$. Setelah mensimulasikan harga saham, akan ditentukan nilai payoff opsi call dengan persamaan (2.1). Setelah mendapatkan payoff opsi call, maka langkah selanjutnya adalah menaksir harga opsi call dengan merata-ratakan payoff dari opsi call tersebut. Untuk menaksir harga opsi call digunakan persamaan (2.11).

Dalam penelitian ini dilakukan simulasi harga opsi call tipe Eropa sebanyak $M$ simulasi, yaitu $M=10, \quad M=100, \quad M=1.000, \quad M=$ $10.000, M=100.000$, dan $M=1.000 .000$.

Selanjutnya dengan bantuan software $R$ diperoleh hasil simulasi harga opsi call tipe Eropa dilanjutkan dengan membandingkan kekonvergenan hasil simulasi harga opsi call tipe Eropa.

Tabel 4.1 Perbandingan Harga Opsi Call Tipe Eropa Menggunakan Simulasi Monte Carlo, Teknik Antithetic Variates dan model Black-Scholes.

\begin{tabular}{|c|c|c|c|c|c|}
\hline \multirow{2}{*}{$M$} & \multicolumn{2}{|c|}{ Simulasi Monte Carlo standar } & \multicolumn{2}{|c|}{$\begin{array}{c}\text { Simulasi Monte Carlo-antithetic } \\
\text { variates }\end{array}$} & $\begin{array}{c}\text { Black- } \\
\text { Scholes }\end{array}$ \\
\cline { 2 - 5 } 10 & Harga opsi & Standard error & Harga opsi & Standard error & \\
\cline { 2 - 5 } 100 & $\$ 19.9666$ & 10.11096 & $\$ 19.13451$ & 6.623272 & \\
1.000 & $\$ 14.69727$ & 2.08202 & $\$ 14.54115$ & 1.413002 & \\
10.000 & $\$ 14.78625$ & 0.60681 & $\$ 14.68850$ & 0.434983 & \multirow{2}{*}{$\$ 14.20281$} \\
100.000 & $\$ 14.50178$ & 0.19422 & $\$ 14.61238$ & 0.137631 & \\
1.000 .000 & $\$ 14.69886$ & 0.06192 & $\$ 14.69801$ & 0.043681 & \\
\end{tabular}

Berdasarkan hasil penelitian pada Tabel 4.1 menunjukkan bahwa jumlah simulasi pada metode yang berbeda menghasilkan standard error dan harga opsi yang berbeda pula. Semakin besar jumlah simulasi, standard error yang dihasilkan akan semakin menurun dan akhirnya mendekati nol. Simulasi Monte Carlo standar berhenti pada simulasi ke-1.000.000 diperoleh harga opsi \$14.69786 dengan standard error 0.01962492. Sedangkan simulasi Monte Carlo dengan teknik antithetic variates berhenti pada simulasi ke-100.000 karena standard error-nya sudah mendekati nol, yaitu 0.04368085 dan harga opsi dianggap konvergen pada $\$ 14.69801$.

Hal ini menunjukkan bahwa simulasi Monte Carlo dengan teknik antithetic variates mampu mengurangi variansi lebih cepat daripada Monte Carlo standar sehingga harga opsi yang diperoleh juga lebih cepat menuju konvergen. 


\section{KESIMPULAN}

\section{Kesimpulan}

Berdasarkan hasil dan pembahasan pada bab sebelumnya dapat disimpulkan bahwa simulasi Monte Carlo dengan menggunakan teknik antithetic variates dapat mengurangi variansi dari Monte Carlo standar. Pengurangan variansi ini menyebabkan simulasi Monte Carloantithetic variates dapat menghasilkan harga opsi yang lebih cepat menuju konvergen dibandingkan dengan simulasi Monte Carlo standar.

\section{Saran}

Artikel ini hanya memfokuskan teknik reduksi varians pada teknik antithetic variates pada opsi call tipe Eropa. Maka diharapkan pada skripsi selanjutnya untuk mengkaji teknik reduksi varians lainnya untuk menentukan harga opsi dan perhitungan harga opsi yang diteliti mencakup opsi tipe Amerika, Asia, dan lain sebagainya.

\section{DAFTAR PUSTAKA}

[1] Azis, Dr. Musdalifah, S.E., dkk. 2015. Manajemen Investasi Fundamental, Teknikal, Perilaku Investor dan Return Saham. Yogyakarta : Deepublish.

[2] Halim, Drs. Abdul, MM., Ak. 2005. Analisis Investasi. Malang: Salemba Empat.

[3] Yanto, Ali Ikhwan Wahyu Dilli. 2015. Penentuan Harga Opsi Tipe Eropa dengan Menggunakan Model Black-Scholes.

[4]Zulfa, Nur Atiqotul. 2015. Analisis Estimasi Volatilitas Indeks Harga Saham Menggunakan Harga Tertinggi, Terendah, Pembukaan, dan Penutupan.

[5] Hull, John C. 2012. Options, Future, and Other Derivatives Eight Edition. Canada : Pearson Education International.

[6] Yahoo finance, [online]. http://www.finance.yahoo.comdiakses tanggal 05 Oktober 2018.

[7] Fxs street, [online]. http://www.fxstreet. web.id/economic-calender/interesest-ratestable/ diakses tanggal 05 Oktober 2018. 